\title{
Disability and progression in Afro-descendant patients with multiple sclerosis
}

\author{
Incapacidade e progressão em pacientes afrodescendentes com esclerose múltipla \\ Juliana Calvet Kallenbach Aurenção', Claudia Cristina Ferreira Vasconcelos' ${ }^{1}$ Luiz Claudio Santos Thuler ${ }^{1,2}$, \\ Regina Maria Papais Alvarenga ${ }^{1,3}$
}

\begin{abstract}
Multiple sclerosis (MS) prevalence is higher in Caucasian (CA) populations, narrowing the analysis of the impact of Afro-descendant (AD) populations in disease outcomes. Even so, recent studies observed that AD patients have a more severe course. The main objective of this study is to confirm and discuss, through a systematic review, that being AD is a risk factor for disability accumulation and/or severe progression in patients with MS. A systematic review of published data in the last eleven years was performed, which evaluated clinical aspects and long term disability in patients with MS. Fourteen studies were included. Of these fourteen articles, thirteen observed a relationship between ancestry and poorer outcome of MS. African ancestry is a condition inherent in the patient and should be considered as an initial clinical characteristic affecting prognosis, and influencing which therapeutic decision to make in initial phases.
\end{abstract}

Keywords: multiple sclerosis; disease progression; disability, Afro-descent.

\section{RESUMO}

A prevalência da esclerose múltipla (EM) é maior em populações caucasianas (CA), o que limita a análise do impacto da Afrodescendencia (AD) nos desfechos da doença. Apesar disto, estudos recentes observaram que a AD determina um curso clínico mais severo. 0 principal objetivo deste estudo é confirmar e discutir, por meio de uma revisão sistemática, que a afrodescendência é um fator de risco para acúmulo de incapacidade e/ou progressão mais severa em pacientes com EM. Foi realizada uma revisão sistemática de trabalhos publicados nos últimos onze anos que avaliaram aspectos clínicos e incapacidade a longo prazo em pacientes com EM. Quatorze artigos foram incluídos. Entre eles, treze observaram uma relação entre AD e pior prognóstico da EM. AD é uma condição inerente ao paciente e deveria ser considerada, assim como as características clínicas relacionadas ao prognóstico, influenciando a decisão terapêutica a ser tomada nas fases iniciais da doença.

Palavras-chave: esclerose múltipla; progressão da doença; incapacidade, afrodescendente.

Multiple sclerosis (MS) is among the most common causes of nontraumatic neurological disability in young adults ${ }^{1}$. Its natural history has been extensively studied in Caucasian (CA) populations, and prognostic factors have been well recognized: being male, late age at the first symptom, high number of relapses in the onset of the disease, and short interval between initial relapses with poor recovery have been identified as predictive factors of long term disability $2,3,4,5,6,7,8,9,10,11$.

While MS is a worldwide disease, its prevalence is higher in populations from western countries in the northern hemisphere compared to those from Africa, Asia and Latin America ${ }^{12}$. Despite this, MS in Afro-descendant (AD) individuals has been described for a long time, mainly in areas where there has been immigration of African natives, such as United States of America, Brazil and the Caribbean region. Recent studies have observed a severe course with higher disability and faster progression in $\mathrm{AD}$ patients ${ }^{13,14,15,16,17}$, and a worse response to disease modifying drugs ${ }^{18}$. Raising awareness of the prognosis of MS in racially mixed populations in available data in literature highlights the growing therapeutic options of disease modifying drugs that are more effective when administered early. The main objective of this study is to confirm and discuss, through a systematic review, that being of $\mathrm{AD}$ heritage is a risk factor for disability accumulation and/or severe progression in patients with MS.

\section{METHODS}

A systematic review of published data between January, 2003 and October, 2014, with AD as a risk factor

\footnotetext{
${ }^{1}$ Universidade Federal do Estado do Rio de Janeiro, Hospital Universitário Gaffrée e Guinle, Rio de Janeiro RJ, Brasil;

${ }^{2}$ Instituto Nacional de Câncer - INCA, Rio de Janeiro RJ, Brasil;

${ }^{3}$ Hospital Federal da Lagoa, Rio de Janeiro RJ, Brasil.

Correspondence:Juliana Calvet Kallenbach Aurenção; Rua Mariz e Barros 775 / $2^{\circ}$ andar; 20270-004 Rio de Janeiro RJ, Brasil; E-mail: julianacka@hotmail.com Conflict of interest: There is no conflict of interest to declare.
}

Received 11 September 2015; Received in final form 06 January 2016; Accepted 25 May 2016. 
for disability accumulation and/or severe progression of MS was performed. It included original articles in English of cross-sectional and cohort studies, prospective and retrospective, that evaluated clinical aspects and long-term disability in patients with MS in the different clinical phenotypes (relapsing-remitting [RR], secondary progressive [SP] and primary progressive [PP]), according to Lublin's and Reingold's definition ${ }^{19}$. Review articles, meta-analyses, editorials and case reports were rejected. Studies with laboratorial and/or image endpoints were also excluded.

The databases MEDLINE, Latin-American and Caribbean Literature in Health Sciences (LILACS), Scientific Electronic Library Online (SciELO) and PubMed were consulted with the following combined descriptors (in English): "multiple sclerosis", "secondary progression", "progression", "primary progression", "African ancestry", "African American”, "African descendants", "Black patients”, "Negro”, "risk factors", "prognostic factors". The abstracts of the selected articles were read independently by two authors (JCKA and CCFV), for inclusion or exclusion from the systematic review. The reviewers reached a consensus on all items. The reviewers evaluated the titles and abstracts of all identified studies and then obtained complete copies of all relevant articles. Any related article's function was used to broaden the search. References of the selected articles were also searched manually. The studies that evaluated the association between $\mathrm{AD}$ ethnicity and progression and/or disability accumulation were fully analyzed. The following items were extracted from each study if available: first author's name, publication year, clinical and demographic factors, number of subjects, clinical impairment, time to reach a certain disability level or time to progression, mean of Expanded Disability Status Scale (EDSS) or progression index stratified by ethnicity.

The electronic research identified 184 studies published with the keywords, combined between them, in PubMed and MEDLINE. Initially, 166 articles were excluded for not being relevant. Eighteen articles were selected, of which a further five were excluded because they were about laboratorial or image aspects. Four articles were excluded for being performed only in a pediatric population or related only to treatment outcomes. By manual search we selected a further nine articles, four of which were excluded for having been published in French and/or for not being related to the main endpoint of this review. The remaining articles were fully analyzed and the STROBE checklist for cohort studies was applied. Studies that had the same source of patients, like the New York State Multiple Sclerosis Consortium (NYSMSC) ${ }^{16,20}$ and North American Research Committee on Multiple Sclerosis (NARCOMS) ${ }^{17,21}$ were only counted once, using the study with the higher number of patients, thus avoiding a duplicate count. Fourteen articles fulfilled the inclusion criteria (Figure).

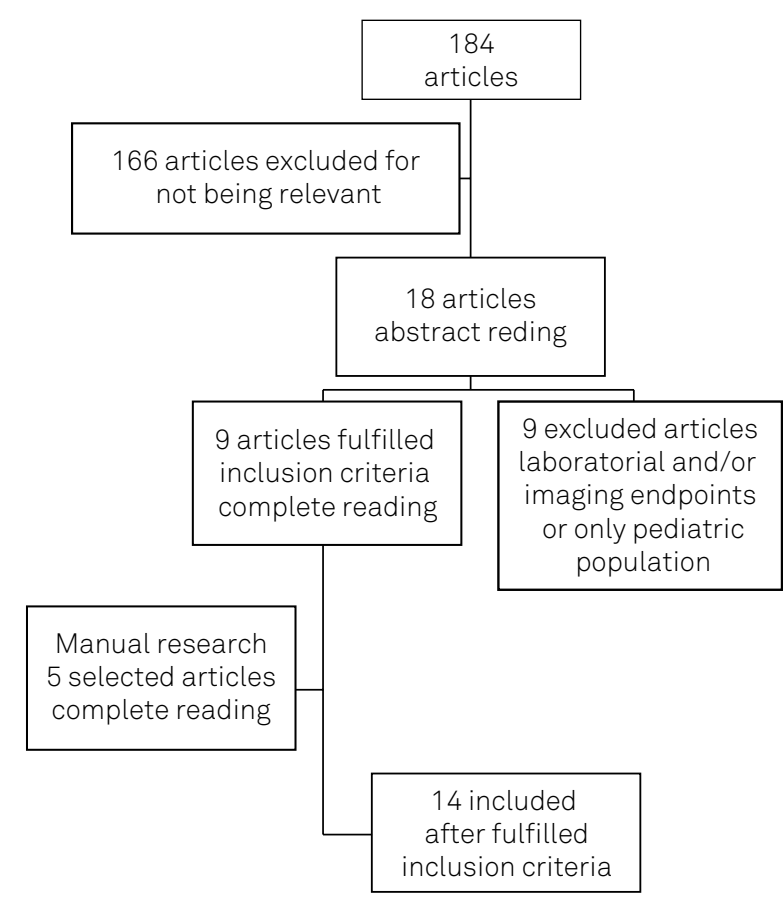

Figure. Flow chart of the search strategy.

\section{RESULTS}

Among the 14 articles considered relevant, nine articles are from North America, three articles from Brazil, and two from Europe. Together, they covered a population of 52,470 patients, 4,068 $\mathrm{AD}(7.8 \%)$ and 48,402 CA (92.2\%). Eleven studies analyzed the three clinical phenotypes of the disease $^{15,16,17,20,21,22,23,24,25,26,27}$, two only evaluated the RR/SP forms ${ }^{2,28}$ and one, just the PP form ${ }^{29}$.

The clinical and demographic characteristics analyzed in twelve studies were: gender, age, race, MS history (age at onset, age at diagnosis, functional system affected), disability status and treatment ${ }^{2,15,16,17,20,21,22,23,26,27,28,29}$. Six studies also evaluated the progression status ${ }^{2,15,26,27,28,29}$.

The ancestry was defined through self-report questionnaires ${ }^{2,15,16,17,20,21,26,27}$, by the presence of one black skin relative up to three previous generations ${ }^{28,29}$, or by the parents' background $^{22}$. One study did not describe how ethnicity was determined ${ }^{23}$.

Different endpoints were adopted: a) the mean or median EDSS at a certain time ${ }^{16,23,26,28}$, b) time to reach disability markers by EDSS 0 and $2^{16}$, EDSS $3^{16,29}$, EDSS $4^{22,27}$, EDSS $5^{16}$, EDSS $6^{2,15,16,22,23,27,29}$, EDSS $7^{2,15,16,23}$, and EDSS $8^{2,16,27,29}$, c) EDSS score in the $4^{\text {th }}$ and $6^{\text {th }}$ year of disease and at last follow-up ${ }^{23}$, in the $5^{\text {th }}$ and $10^{\text {th }}$ year and at the last follow-up ${ }^{28}$, d) time to start of the progressive phase $e^{15,26,27,28,29}$, e) analysis of benign and malignant courses ${ }^{2,28}$. Besides the EDSS, another three scales were applied for assessing the disability: the Multiple Sclerosis Severity Score (MSSS) ${ }^{20}$, Patient Determined Disease Steps (PDDS) ${ }^{17,21}$ and ADL Long Form Scale $^{24,25}$ (Table 1 and Table 2). 
Table 1. Summarizes the studies that have used the Kurtzke Expanded Disability Status Scale (EDSS) to evaluate disability and functional capacity.

\begin{tabular}{|c|c|c|}
\hline Author,y. & $A D(n ; \%)$ in the cohort & Results concerning $A D$ population (compared to $C A$ ) \\
\hline Kaufman et al. $2003^{26}$ & $95 ; 12.9$ & Higher EDSS mean after 4 years of disease and shorter time to progression \\
\hline Cree et al. $2004^{15}$ & $375 ; 46.7$ & Shorter time to progression and EDSS 6 and 7 \\
\hline Naismith et al. $2006^{23}$ & $79 ; 49.7$ & Higher EDSS mean at diagnosis and after 4 and 6 years of follow up \\
\hline Debouverie et al. $2007^{22}$ & $211 ; 6.7$ & Shorter time to EDSS 4 and 6 \\
\hline Weinstock-Guttman et al. $2008^{16}$ & $329 ; 5.9$ & Higher EDSS mean after $5,10,15$ and 20 years of disease \\
\hline Vasconcelos et al. $2010^{29}$ & $23 ; 35.4$ & Shorter time to EDSS 3, 6 and 8 \\
\hline Vasconcelos et al. $2012^{28}$ & $33 ; 22.0$ & Shorter time to progression and higher EDSS median after 5 and 10 years of follow up \\
\hline Koffman et al. $2013^{27}$ & $43 ; 50.0$ & Shorter time to EDSS 4, 6, 8 and progression \\
\hline
\end{tabular}

y:years; AD: afro descendants; CA: Caucasians.

Table 2. Summary of clinical and demographic factors associated with afro descendants patients and the studies that have used other scales to evaluate disability and functional capacity.

\begin{tabular}{|c|c|c|}
\hline Author, y. & $A D(n ; \%)$ in the cohort & Results concerning AD population (compared to CA) \\
\hline Kaufman et al. $2003^{26}$ & $95 ; 12.9$ & Had advanced age at onset and shorter disease duration than CA \\
\hline Buchanan et al. $2004^{24}$ & $1367 ; 12.8$ & $\begin{array}{l}\text { Were admitted to nursing home younger; more frequency of AD with worse } \\
\text { cognitive performance; were less independent in ADL Long Form Scale }\end{array}$ \\
\hline Cree et al. $2004^{15}$ & $375 ; 46.7$ & $\begin{array}{c}\text { Were older at onset and had shorter disease duration, had early diagnosis and } \\
\text { early treatment and had more polysymptomatic relapses }\end{array}$ \\
\hline Buchanan et al. $2006^{25}$ & $461 ; 11.3$ & $\begin{array}{l}\text { Were admitted to nursing home younger; more frequency of AD with worse } \\
\text { cognitive performance; were less independent in ADL Long Form Scale }\end{array}$ \\
\hline Naismith et al. $2006^{23}$ & $79 ; 49.7$ & $\begin{array}{l}\text { Had a higher frequency of progressive forms, ataxia, tremor and cognitive } \\
\text { dysfunction; Lower frequency of benign forms among ADs }\end{array}$ \\
\hline Marrie et al. $2006^{21}$ & $1017 ; 4.7$ & Early diagnosis and shorter disease duration; PDDS median was higher \\
\hline Debouverie et al. $2007^{22}$ & $211 ; 6.7$ & $\begin{array}{c}\text { Younger age at onset and shorter mean of follow up; had more frequently } \\
\text { incomplete recovery from the first relapse, shorter time interval between } \\
\text { first and second relapse and higher number of relapses in the first five } \\
\text { years of the disease }\end{array}$ \\
\hline $\begin{array}{l}\text { Weinstock-Guttman et al. } \\
2008^{16}\end{array}$ & $329 ; 5.9$ & Were diagnosed younger; cognitive impairment was more frequent \\
\hline Kister et al. $2010^{20}$ & $419 ; 6.7$ & $\begin{array}{l}\text { Shorter disease duration at diagnose; lower AD frequency of benign form; } \\
\text { higher AD frequency of malignant form; higher median MSSS }\end{array}$ \\
\hline Vasconcelos et al. $2010^{29}$ & $23 ; 35.4$ & Men predominant in $\mathrm{AD}$ group and $\mathrm{ADs}$ had shorter disease duration \\
\hline Buchanan et al. $2010^{17}$ & $1313 ; 4.6$ & $\begin{array}{c}\text { Mean age at NARCOMS enrolment was lower among AD. ADs had shorter } \\
\text { disease duration, had severe gait disability, fatigue, bowel and bladder } \\
\text { incontinence, spasticity, visual and cognitive impairment, depression, tremor } \\
\text { and loss of coordination than CAs; were more frequent represented at higher } \\
\text { PDDS scores }\end{array}$ \\
\hline Vasconcelos et al. $2012^{28}$ & $33 ; 22.0$ & $\begin{array}{l}\text { Older at disease onset; more incomplete recovery and higher number of } \\
\text { relapses; benign form less frequent in } A D \text {; malignant form more frequent in } A D\end{array}$ \\
\hline Koffman et al. $2013^{27}$ & $43 ; 50.0$ & More cognitive impairment; MSSS mean was higher \\
\hline
\end{tabular}

Progression was considered as the increase of one point in the EDSS scale, not attributed to relapse, maintained for six months or more, without improvement, or for a progressive worsening of symptoms in six articles ${ }^{2,15,26,27,28,29}$. The definition of a benign course was an EDSS score of 3 or less after ten years of disease and a malignant course was defined as an EDSS score of 6 or higher after five years of disease, in two articles ${ }^{2,28}$.

\section{DISCUSSION}

In 1962, Alter published the research results of MS in Blacks from New York and affirmed that the disease was rare in this group, however without significant differences between Blacks and Whites regarding clinical manifestations $^{30}$. After 33 years, in 1995 the first Brazilian article was published in which a frequency of $31.4 \% \mathrm{AD}$ among MS patients ${ }^{31}$ was described. Unlike that observed by Alter, in the Brazilian study there was a higher frequency of $\mathrm{AD}$ women with motor relapses compared to CA women, who had more relapses of visual and cerebellar type. Nowadays it is known that both $\mathrm{AD}$ ethnicity and motor impairment are independent predictors of a poorer long-term outcome. Although analyses of the impact of $\mathrm{AD}$ ethnicity in disease outcomes are still scarce, in the last ten years, studies with racially mixed populations, such as in North America and 
Brazil, have pointed to differences between the disease outcome in $\mathrm{CA}$ and $\mathrm{AD}$ patients.

Considering that MS is a worldwide disease, studies on the influence of ethnicity have been performed in only four locations, three of them (USA, Brazil and Caribbean region) probably due to the African background during colonization.

The frequency of $\mathrm{AD}$ patients in the analyzed studies was not more than half of each cohort. In four studies, self-response questionnaires were used in which the patients classified themselves as $\mathrm{CA}$ or $\mathrm{AD}$, a fact that may explain the low frequency of $\mathrm{AD}$ observed in them ${ }^{16,17,20,21}$. Despite the lower frequency of $\mathrm{AD}$ studies, the majority of them showed a worse outcome in the $\mathrm{AD}$ group. It is worth noting that two studies did not exclude patients with the diagnosis of neuromyelitis optica ${ }^{15,26}$, a circumstance that may have caused bias, due to neuromyelitis optica being more common in $\mathrm{AD}$ than CA patients $^{32}$ and having a more severe course.

Diverse risk factors for severe progression have been identified and extensively discussed in the literature; nevertheless, these results are not always consistent between studies, due to different classifications and methods of analysis, and genetic variability of the studied populations. In relation to these prognosis factors, in this systematic review it was observed that $\mathrm{AD}$ patients were more likely to be older at onset ${ }^{26}$, have incomplete recovery of relapses, shorter inter-attack intervals and more relapses in the first five years of disease ${ }^{22}$. Afro-descendants were younger when they presented for medical care ${ }^{17,26}$, probably due to severe relapses, they sought neurological care in a shorter time, and when admitted to nursing homes, had a higher disability score, ${ }^{24,25}$ with more motor limitation ${ }^{23,24}$ and more severe and rapid cognitive impairment ${ }^{16,24}$. More $\mathrm{AD}$ patients were bowel or bladder incontinent than CA patients on admission to nursing homes ${ }^{25}$. Even though the studies adopted different disability markers in the EDSS scale ${ }^{15,16,22,23,26,27,28,29}$, it was possible to observe that $\mathrm{AD}$ patients reached these markers in shorter times or had higher EDSS mean or median scores after a set time of follow-up. Despite the fact that the complex association between immunogenetic and ethnic factors has not yet been fully elucidated, the worse and faster evolution observed in Afro-Brazilian patients, as well as African-Americans and Afro-Europeans suggests a greater ethnic influence in the progression of multiple sclerosis.

Correlation between $\mathrm{AD}$ ethnicity and the endpoints was observed in the majority of the studies, with the exception of the study performed in the city of Campinas ${ }^{2}$, in the southeast region of Brazil, where most of the genetic ancestry is European, with $\mathrm{AD}$ ethnicity corresponding to $7.4 \%^{33,34}$. Forty percent of the patients analyzed presented for less than five years of follow-up, a fact that can cause bias in the analysis of long-term outcomes.

The EDSS scale was the most used in MS studies, and, even when less common scales were used, $\mathrm{AD}$ patients had a higher chance of developing severe disability and a poorer outcome.
In studies that analyzed progression ${ }^{2,15,26,27,28,29}, \mathrm{AD}$ patients had an unfavorable disease course, the progressive phase of the disease was reached faster by $\mathrm{AD}$ patients ${ }^{15,28}$ with a higher progression index ${ }^{26}$ and they had a higher risk for malignant $\mathrm{MS}^{28}$. Caucasians had a greater risk $^{28}$ and a higher frequency ${ }^{26}$ of the benign form.

In relation to the clinical phenotype, $\mathrm{AD}$ patients had a higher incidence of the PP form and lower incidence of the RR form ${ }^{23}$. With regard to the higher frequency of men in the $\mathrm{AD}$ group $^{29}$, male gender has been identified as a risk factor for the worst result for the illness, therefore studies with multivariate analysis would clarify whether the two factors together increase the risk. However, considering that for PPMS the female/male ratio is almost 1:1, in the study that only evaluated the PP form, the high number of males in the $\mathrm{AD}$ group could be considered as a bias. Furthermore, in this same study ${ }^{29}$, even though PPMS had a worse prognosis, $\mathrm{AD}$ patients reached disability markers in a shorter time, reinforcing the greater disease severity in those with African ancestry.

Although this systematic review has considered demographic, clinical and evolutive aspects that could lead to longterm disability and progression among $\mathrm{AD}$ patients, some studies correlate imaging and immunological aspects in the cerebrospinal fluid among $\mathrm{AD}$ patients that could lead to a worse outcome. Howard et al. ${ }^{14}$, in 2012, showed that AD patients had higher lesion burden compared to CA patients and showed a more severe disease course. Weinstock-Guttman et al. ${ }^{35}$, in 2010 showed that AD patients had increased tissue damage and higher lesion volumes, compared to White Americans. Rinker et al. ${ }^{36}$, in 2007, observed that AD patients had a more active immune response in the cerebrospinal fluid compared to CA patients with MS but this did not predict earlier progression, and Gama et al. ${ }^{37}$, in 2015 , showed that the presence of oligoclonal bands in the cerebrospinal fluid were significantly associated with $\mathrm{AD}$ origin, and progressive forms despite ethnicity.

Regarding treatment, Cree et al. ${ }^{18}$ in 2005 , Jeannin et al..$^{38}$ in 2011 and Klineova et al. ${ }^{39}$ in 2012 , showed that AD patients had a worse response to drug modifying treatment when compared to CA patients.

Although world statistics point to unfavorable socioeconomic conditions among $\mathrm{AD}$ individuals, especially on the American continent, it is very important to call attention to the fact that in most of the studies ${ }^{2,15,16,17,20,21,22,23,24,25,28,29}$, the access to medical care, diagnosis and treatment was reported to be similar for $\mathrm{AD}$ and $\mathrm{CA}$ patients. In one of the studies, the mean and median time to diagnosis was shorter in $\mathrm{AD}$ patients ${ }^{17}$. These data suggest that socioeconomic factors may not influence the results. This observation lets us infer that $\mathrm{AD}$ ethnicity confers higher risk for a worse outcome despite early diagnosis and treatment, however, current accessibility to more effective drugs that are indicated for disease forms with potentially severe evolution could be an option. 


\section{FINAL REMARKS}

In this systematic review on the influence of $\mathrm{AD}$ on the clinical course of MS, it was possible to observe that although the disease is more common in $\mathrm{CAs}$, the $\mathrm{AD}$ condition creates a greater risk for adverse outcomes such as disability and earlier progression. In a mixed MS population, as well as well-known prognostic factors, $\mathrm{AD}$ ethnicity should be considered at the time of the therapeutic decision.

\section{References}

1. World Health Organization. Atlas multiple sclerosis resources in the world 2008. Geneva: World Health Organization; 2008.

2. Damasceno A, Von Glehn F, Brandão CO, Damasceno BP, Cendes F. Prognostic indicators for long-term disability in multiple sclerosis patients. J Neurol Sci. 2013;324(1-2):29-33. doi:10.1016/j.jns.2012.09.020

3. Scalfari A, Neuhaus A, Degenhardt A, Rice GP, Muraro PA, Daumer $M$ et al. The natural history of multiple sclerosis, a geographically based study 10: relapses and long-term disability. Brain. 2010;133(7):1914-29. doi:10.1093/brain/awq118

4. Hammond SR, McLeod JG, Macaskill P, English DR. Multiple sclerosis in Australia: prognostic factors. J Clin Neurosci. 2000;7(1):16-9. doi:10.1054/jocn.1998.0107

5. Amato MP, Ponziani G. A prospective study on the prognosis of multiple sclerosis. Neurol Sci. 2000;21(4 Suppl 2):S831-8. doi:10.1007/s100720070021

6. Confravreux C, Vukusic S, Adeleine P. Early clinical predictors and progression of irreversible disability in multiple sclerosis: an amnesic process. Brain. 2003;126(4):770-82. doi:10.1093/brain/awg081

7. Debouverie M. Gender as a prognostic factor and its impact on the incidence of multiple sclerosis in Lorraine, France. J Neurol Sci. 2009;286(1-2):14-7. doi:10.1016/j.jns.2009.07.012

8. Koch M, Kingwell E, Rieckmann P, Tremlett $\mathrm{H}$. The natural history of secondary progressive MS.J Neurol Neurosurg Psychiatry. 2010;81(9):1039-43. doi:10.1136/jnnp.2010.208173

9. Scalfari A, Neuhaus A, Daumer M, Ebers GC, Muraro PA. Age and disability accumulation in multiple sclerosis. Neurology. 2011;77(12):1246-52. doi:10.1212/WNL.0b013e318230a17d

10. Scalfari A, Neuhaus A, Daumer M, DeLuca GC, Muraro PA, Ebers GC. Early relapses, onset of progression, and late outcome in multiple sclerosis. JAMA Neurol. 2013;70(2):214-22. doi:10.1001/jamaneurol.2013.599

11. Confavreux C, Vukusic S. Natural history of multiple sclerosis: a unifying concept. Brain. 2006;129(3):606-16. doi:10.1093/brain/awl007

12. KingwellE, Marriott JJ, Jetté N, Pringsheim T, Makhani N, Morrow SA et al. Incidence and prevalence of multiple sclerosis in Europe: a systematic review. BMC Neurol. 2013;13(1):128. doi:10.1186/1471-2377-13-128

13. Johnson BA, Wang J, Taylor EM, Caillier SJ, Herbert J, Khan OA et al. Multiple sclerosis susceptibility alleles in African Americans. Genes Immun. 2010;11(4):343-50. doi:10.1038/gene.2009.81

14. Howard J, Battaglini M, Babb JS, Arienzo D, Holst B, Omari $M$ et al. MRI correlates of disability in African-Americans with multiple sclerosis. PLoS One. 2012;7(8):e43061. doi:10.1371/journal.pone.0043061

15. Cree BA, Khan O, Bourdette D, Goodin DS, Cohen JA, Marrie RA et al. Clinical characteristics of African Americans vs Caucasian Americans with multiple sclerosis. Neurology. 2004;63(11):2039-45. doi:10.1212/01.WNL.0000145762.60562.5D

16. Weinstock-Guttman B, Jacobs LD, Brownscheidle CM, Baier M, Rea DF, Apatoff BR et al. Multiple sclerosis characteristics in African American patients in the New York State
Multiple Sclerosis Consortium. Mult Scler. 2003;9(3):293-8. doi:10.1191/1352458503ms909oa

17. Buchanan RJ, Zuniga MA, Carrillo-Zuniga G, Chakravorty BJ, Tyry T, Moreau RL et al. Comparisons of Latinos, African Americans, and Caucasians with multiple sclerosis. Ethn Dis. 2010;20(4):451-7.

18. Cree BAC, Al-Sabbagh A, Bennett R, Goodin D. Response to interferon beta-1a treatment in African American multiple sclerosis patients. Arch Neurol. 2005;62(11):1681-3. doi:10.1001/archneur.62.11.1681

19. Lublin FD, Reingold SC. Defining the clinical course of multiple sclerosis: results of an international survey. Neurology. 1996;46(4):907-11.doi:10.1212/WNL.46.4.907

20. Kister I, Chamot E, Bacon JH, Niewczyk PM, De Guzman RA, Apatoff B et al. Rapid disease course in African Americans with multiple sclerosis. Neurology. 2010;75(3):217-23. doi:10.1212/WNL. 0b013e3181e8e72a

21. Marrie RA, Cutter G, Tyry T, Vollmer T, Campagnolo D. Does multiple sclerosis-associated disability differ between races? Neurology. 2006;66(8):1235-40. doi:10.1212/01.wnl.0000208505.81912.82

22. Debouverie M, Lebrun C, Jeannin S, Pittion-Vouyovitch S, Roederer T, Vespignani H. More severe disability of North Africans vs Europeans with multiple sclerosis in France. Neurology. 2007;68(1):29-32. doi:10.1212/01.wnl.0000250347.51674.d7

23. Naismith RT, Trinkaus K, Cross AH. Phenotype and prognosis in African-Americans with multiple sclerosis: a retrospective chart review. Mult Scler. 2006;12(6):775-81. doi:10.1177/1352458506070923

24. Buchanan RJ, Martin RA, Zuniga M, Wang S, Kim M. Nursing home residents with multiple sclerosis: comparisons of African American residents to white residents at admission. Mult Scler. 2004;10(6):660-7. doi:10.1191/1352458504ms1086oa

25. Buchanan RJ, Martin RA, Wang S, Kim MS. Racial analysis of longerstay nursing home residents with MS. Ethn Dis. 2006;16:160-5.

26. Kaufman MD, Johnson SK, Moyer D, Bivens J, Norton HJ. Multiple sclerosis: severity and progression rate in African Americans compared with whites. Am J Phys Med Rehabil. 2003;82(8):582-90. doi:10.1097/01.PHM.0000078199.99484.E2

27. Koffman J, Gao W, Goddard C, Burman R, Jackson D, Shaw P et al. Progression, symptoms and psychosocial concerns among those severely affected by multiple sclerosis: a mixed-methods cross-sectional study of Black Caribbean and White British people. PLoS One. 2013;8(10):e75431. doi:10.1371/journal.pone.0075431

28. Vasconcelos CCF, Santos GAC, Thuler LC, Camargo SM, Alvarenga RP. African ancestry is a predictor factors to secondary progression in clinical course of multiple sclerosis. ISRN Neurol. 2012;2012:410629. doi:5402/2012/410629

29. Vasconcelos CCF, Thuler LCS, Santos GAC, Alvarenga MP, Alvarenga MP, Camargo SMG et al. Differences in the progression of primary progressive multiple sclerosis in Brazilians of African descent versus white Brazilian patients. Mult Scler. 2010;16(5):597-603. doi:10.1177/1352458509360987

30. Alter M, Bethesd A. Multiple sclerosis in the negro. Arch Neurol. 1962;7(2):83-91. doi:10.1001/archneur.1962.04210020005001 
31. Papais-Alvarenga RM, Santos CMM, Colin DD, Peixoto EC, Camargo SMGG. Esclerose múltipla (EM): influência do sexo e da etnia no perfil clínico de 88 pacientes no município do Rio de Janeiro. Rev Bras Neurol. 1995;31(2):89-98.

32. Alvarenga RMP, Vasconcelos CCF, Leon SVA et al. The impact of diagnostic criteria for neuromyelitis optica in patients with MS: a 10-year follow-up of the South Atlantic project. Mult Scler. 2014;20(3):374-81. doi:10.1177/1352458513495580

33. Callegaro D, Goldbaum M, Morais L, Tilbery CP, Moreira MA, Gabbai AA et al. The prevalence of multiple sclerosis in the city of São Paulo, Brazil, 1997. Acta Neurol Scand. 2001;104(4):208-13. doi:10.1034/j.1600-0404.2001.00372.x

34. Pena SD, Di Pietro G, Fuchshuber-Moraes M, Genro JP, Hutz MH, Kehdy FS et al. The genomic ancestry of individuals from different geographical regions of Brazil is more uniform than expected. PLoS One. 2011;6(2):e17063. doi:10.1371/journal.pone.0017063

35. Weinstock-Guttman B, Ramanathan M, Hashmi K, Abdelrahman N, Hojnacki D, Dwyer MG et al. Increased tissue damage and lesion volumes in African Americans with multiple sclerosis. Neurology. 2010;74(7):538-44. doi:10.1212/WNL.0b013e3181cff6fb

36. Rinker JR 2nd, Trinkaus K, Naismith RT, Cross AH. Higher IgG index found in African Americans versus Caucasians with multiple sclerosis. Neurology. 2007;69(1):68-72. doi:10.1212/01.wnl.0000265057.79843.d9

37. Gama PD, Machado LR, Livramento JÁ, Gomes HR, Adoni T, Morales RR et al. Oligoclonal bands in cerebrospinal fluid of black patients with multiple sclerosis. BioMed Res Int. 2015;2015:217961. doi:10.1155/2015/217961

38. Jeannin S, Deschamps R, Chausson N, Cabre P. Response to interferon-Beta treatment in afro-caribbeans with multiple sclerosis. Mult Scler Int. 2011;950126. doi:10.1155/2011/950126

39. Klineova S, Nicholas J, Walker A. Response to disease modifying therapies in African Americans with multiple sclerosis. Ethn Dis. 2012;22(2):221-5. 